\title{
Evaluation of self-feeders as a tool to study diet preferences in groups of Atlantic cod (Gadus morhua)
}

\author{
Sandie Millot $^{1, \text { a }}$, Jonatan NILSSON ${ }^{2}$, Jan Erik FosSEIDENGEN ${ }^{2}$, Marie-Laure BÉGOUT $^{1}$ \\ and Tore KRISTIANSEN ${ }^{2}$ \\ 1 Ifremer, Laboratoire Ressources halieutiques, place Gaby Coll, BP 7, 17137 L'Houmeau, France \\ 2 Institute of Marine Research, PO Box 1870, Nordnes, 5817 Bergen, Norway
}

Received 19 March 2012; Accepted 21st June 2012

\begin{abstract}
Among other applications, self-feeding has been used to study food preferences in fish allowing them to choose between feeders with different food content. Preference tests assume that (i) trigger actuations are motivated by appetite, (ii) fish can learn which feeder contains which food and discriminate between feeders solely on the basis of their content, and (iii) in groups of fish, the triggering preferences is representative for the individuals of the group. We studied individual triggering behaviour in four groups of 14 Atlantic cod (length of $34 \pm 2 \mathrm{~cm}$, weight of $424 \pm 102 \mathrm{~g}$, mean $\pm \mathrm{SE}$, water temperature comprised between $7-8{ }^{\circ} \mathrm{C}$ ) that were first given the choice between two self-feeders with identical content (Period 1 of 14 days) and subsequently with one feeder full and the other empty (Period 2 of 14 days). In all four groups, one or two individuals performed the majority of the actuations, and in three groups the high triggering fish was a female high-ranked for size and growth rate. Cod displayed a preference for one of the two feeders despite their identical content. When the preferred feeder was emptied, the preference switched after one to eight days but both feeders were still actuated throughout the experiment. In conclusion, the assumption that actuation frequency reflects food preference and is representative for the individuals of the group may not be true, at least for Atlantic cod. If aiming at determining preferences representative for the whole population multiple representative fish should be kept isolated in separate tanks, with self-feeders containing each food option, on each tank.
\end{abstract}

Keywords: Learning / Self-feeding / Social status / Behaviour / Coping abilities / Gadidae

\section{Introduction}

The ability of animals to learn to carry out simple tasks in order to gain a reward, such as food, exemplifies a type of adaptive behaviour referred to as instrumental or operant learning (Skinner 1938; Davey 1989). Thus, self-feeding can be seen as a case of instrumental learning, in which positive reinforcement is achieved by dispensing food each time a trigger is actuated (Alanärä 1996).

Self-feeding devices are widely used to study different aspects of fish behaviour, such as feeding activity (Azzaydi et al. 1998), group dynamics (Millot and Bégout 2009), operant learning ability (Nilsson and Torgersen 2010) and food preferences (Aranda et al. 2000, 2001). In food preference tests fish generally have access to two or more self-feeders containing different food types (Sánchez-Vázquez et al. 1998; Aranda et al. 2000, 2001; Montoya et al. 2011) and higher triggering rate on one feeder is usually considered as a preference for one food type over the other types. However, there are a number of

a Corresponding author: sandiemillot@yahoo.fr assumptions that should be taken into account when doing this kind of test.

Firstly, one should assume that each trigger actuation is motivated by fish appetite. However, fish may actuate the trigger for other reasons, e.g. curiosity or accidentally (Nilsson and Torgersen 2010), and this is always the case for the first actuations before the fish have learnt the association between their own behaviour (trigger actuations) and its consequences (food delivery). An important aspect is also that to actuate the trigger in a predictable way, the fish must learn the trick (i.e. how to pull the trigger) and not only the association between the trigger and the food (Fernö et al. 2011).

Secondly, one should assume that fish can learn not only to activate the feeders when hungry, but also learn which feeder contains which food type, and thereby discriminate between feeders on the basis of their food content rather than any other attributes that could make one feeder preferred over the others. Preference for one feeder over another one containing the same type of food may sometimes be the case (Geurden et al. 2005; Aranda et al. 2000), but can be controlled for by switching food types between feeders. The ability of fish to discriminate between feeders on the basis of the food content has been 
described for several species (Attia et al. 2012). For instance, Montoya et al. (2011) found that gilthead sea bream (Sparus aurata) given the choice between two self-feeders containing either an oxidised diet or a non-oxidised control diet, within 10 days developed a preference for the feeder containing the control diet.

Thirdly, so as to conclude that the most used feeder contains the preferred food type by the fish population, one must assume that most fish use the feeder at a similar rate, or at least that the active individuals have similar needs and preferences compared to an average individual. However, several studies with different species have found that only one or a few individuals (high triggering fish; HTF) in a group account for the majority of the trigger actuations and these individuals may deviate from the group mean in terms of size, social status, and/or sex. In rainbow trout (Oncorhynchus mykiss), Arctic charr (Salvelinus alpinus) and sea bass (Dicentrarchus labrax) there is a good correlation between the social rank and the number of self-feeder actuations: one or two dominant fish performed the majority of actuations (Alanärä and Brännäs 1993, 1996; Brännäs and Alanärä 1993, 1994; Millot et al. 2008; Millot and Bégout 2009). In Arctic charr and sea bass there is a strong negative correlation between feeding demand (and/or growth rate) and brain serotonergic activity; the main neurological marker of chronic social stress in fish (Alanärä et al. 1998; Di-Poï et al. 2007). Thus, the assumption that the HTFs are representative of the population may not be true.

We aimed to evaluate the basic fundamentals of the selffeeding behaviour of Atlantic cod before future use of selffeeders for the purpose of studying food preference. Cod has recently been found to learn self-feeding rapidly (Nilsson and Torgersen 2010), but there are no published data about the individual and group feeding dynamics of cod using self-feeders and about the capacity of this species to adapt to a switch in food content of feeders. Thus, in the present paper we studied individual differences in triggering activity of cod given the choice between two feeders initially containing the same food type, and later with one feeder empty, i.e. with actuations never being rewarded, and the other feeder full, with actuations always being rewarded.

The current study tested for Atlantic cod the hypotheses that (1) trigger actuations are mainly motivated by fish appetite, (2) cod will discriminate between feeders on basis of their content, and (3) the trigger actuations are representative of the population needs.

\section{Materials and methods}

\subsection{Experimental set up}

The experiment was run in Research station Austevoll of the Institute of Marine Research southwest of Bergen, Norway. The experiment was carried out with four groups of 14 cod. Four tanks $\left(0.75 \mathrm{~m}^{3}\right.$ each) were supplied with seawater from flow through system at a rate of $50 \mathrm{~L} \mathrm{~min}^{-1}$. All tanks were in the same room. Water temperature remained at $7-8{ }^{\circ} \mathrm{C}$, oxygen saturation above $90 \%$ at the water-outlet, and salinity around 35 ppt. Each tank were continuously lit by a $35 \mathrm{~W}$ halogen spotlight hanging $1.5 \mathrm{~m}$ above the water surface.
There were two self-feeding devices (InnovaFeed, InnovAqua SLL, Sevilla, Spain) for each tank. A feeder device comprised a pull string sensor with a plastic bead at the end for the fish to bite and a control box connected to a computer. At each actuation (pull of the string) a signal was sent to the control box which started the feeder (ArvoTec TD2000, ArvoTec, Huutokoski, Finland) for a duration of one second, releasing on average $0.8 \mathrm{~g}$ of food (Skretting Amber Neptun, $5 \mathrm{~mm}$, containing $52 \%$ of crude protein and $18 \%$ of lipid according to the manufacturer). Each actuation was recorded on the computer. A small light bulb was connected to each feeding device and switched on when the feeder was actuated. The bulb was placed in an open container above the tank so that it could not be seen by the fish. A colour video camera (VNSVUC-Z10, Scan Secure AS, Horten, Norway) was positioned above each feeder, such that the light bulb, the self-feeder, and the area where the pellets dropped into the water (around $60 \mathrm{~cm}$ downstream the self-feeder) were covered by the field of view. The cameras were controlled via the GV-1120 Multicam Surveillance System (GeoVision Inc., Taipei, Taiwan). The cameras were always recording but the videos storage were switched on by a light detection system. Light detection was restricted to the part of the camera containing the light bulb. As a trigger actuation switched on the bulb it also started video storage. A buffer system in the camera made it possible to store recordings of some time before the light bulb was switched on. Therefore, each video recording included the time interval from $15 \mathrm{~s}$ before to $15 \mathrm{~s}$ after each trigger actuation, making it possible to record each successful trigger actuation and the fish that performed it (see below).

\subsection{Experimental fish}

The cod were hatched in late March 2008, released into a seawater pond (Parisvannet) northwest of Bergen, Norway, shortly after hatching and transferred to sea cages at the same location in June. In September, seven months before the start of the experiment, they were moved to indoor tanks at the Research station at Austevoll where the experiment was carried out. The fish were around 13 months old at the start of the experiment. Two days before the start of the experiment (26 April 2009), fish were anesthetized with a solution of $5 \mathrm{mg} \mathrm{L}^{-1}$ of methomidate (Marnil TM, Wildlife Labs, inc., Fort Collins, USA), measured for length and weight $(32 \pm 2 \mathrm{~cm}, 364 \pm$ $71 \mathrm{~g}$, mean $\pm \mathrm{SE}$ ) and individually tagged with a colour bead $(10 \mathrm{~mm} ; 0.5 \mathrm{~g})$ stitched in the flesh under the dorsal fin to enable identification during video analysis. The fish were again measured for length and weight $(34 \pm 2 \mathrm{~cm}, 424 \pm 102 \mathrm{~g}$, mean $\pm \mathrm{SE}$ ) on the last day of the 28-day experiment (Table 1). During the 2-day recovery period between tagging and the start of the experiment, fish were fed by hand ad libitum in the experimental tanks. To avoid fish becoming familiar with the triggering devices before the start of the experiment, the strings were kept outside the tank during the recovery period.

\subsection{Procedure}

The experiment was carried out from 28 April 2009 to 25 May 2009 with 14 cod in each of the 4 tanks. The experiment 
Table 1. Number of trigger actuations per individual for each experimental period (14 days each, Period 1: $P 1 ;$ Period 2: $P 2)$, sex, initial and final body weight, body condition factor $(K), S G R$ and the individual ranks for each variable (1 to 5 ).

\begin{tabular}{|c|c|c|c|c|c|c|c|c|c|c|c|c|c|c|}
\hline \multirow[t]{3}{*}{ Tank } & \multirow[t]{3}{*}{ Fish id } & \multicolumn{2}{|c|}{$\begin{array}{c}\text { Trigger } \\
\text { actuations }\end{array}$} & \multirow[t]{3}{*}{ Sex } & \multicolumn{2}{|c|}{ Body weight } & \multicolumn{2}{|c|}{$K$} & \multirow{3}{*}{$\begin{array}{r}S G R \\
5\end{array}$} & \multicolumn{5}{|c|}{ Rank } \\
\hline & & $P 1$ & $P 2$ & & Initial & Final & Initial & Final & & 1 & 2 & 3 & 4 & 5 \\
\hline & & & & & 1 & 2 & 3 & 4 & & & & & & \\
\hline \multirow{14}{*}{1} & $1-1$ & 227 & 248 & $\bar{F}$ & 398 & 525 & 1.1 & 1.1 & 1.0 & 2 & 1 & 9 & 6 & 2 \\
\hline & $1-2$ & 8 & 3 & M & 322 & 356 & 1.1 & 1.2 & 0.4 & 8 & 7 & 10 & 2 & 9 \\
\hline & $1-3$ & 5 & 4 & M & 356 & 444 & 1.2 & 1.2 & 0.8 & 5 & 3 & 3 & 1 & 4 \\
\hline & $1-4$ & 3 & 22 & M & 391 & 503 & 1.2 & 0.9 & 0.9 & 3 & 2 & 4 & 13 & 3 \\
\hline & $1-5$ & 3 & 0 & M & 294 & 326 & 1.1 & 1.1 & 0.4 & 11 & 10 & 6 & 8 & 8 \\
\hline & $1-6$ & 2 & 4 & M & 282 & 321 & 1.0 & 1.1 & 0.5 & 12 & 11 & 11 & 5 & 6 \\
\hline & $1-7$ & 2 & 0 & - & 464 & 387 & 1.3 & 1.1 & -0.6 & 1 & 5 & 1 & 11 & 13 \\
\hline & $1-8$ & 1 & 1 & M & 312 & 423 & 1.0 & 1.1 & 1.1 & 9 & 4 & 12 & 4 & 1 \\
\hline & $1-9$ & 1 & 1 & $\mathrm{~F}$ & 259 & 293 & 1.1 & 1.2 & 0.4 & 14 & 13 & 7 & 3 & 7 \\
\hline & $1-10$ & 1 & 2 & $\mathrm{~F}$ & 342 & 367 & 1.1 & 1.1 & 0.3 & 6 & 6 & 8 & 9 & 10 \\
\hline & $1-11$ & 0 & 0 & M & 298 & 355 & 1.0 & 1.0 & 0.6 & 10 & 8 & 13 & 12 & 5 \\
\hline & $1-12$ & 0 & 0 & M & 282 & 299 & 1.2 & 1.1 & 0.2 & 13 & 12 & 5 & 7 & 11 \\
\hline & $1-13$ & 0 & 1 & M & 382 & 353 & 1.2 & 1.1 & -0.3 & 4 & 9 & 2 & 10 & 12 \\
\hline & $1-14$ & 0 & 4 & M & 329 & 277 & 1.0 & 0.8 & -0.6 & 7 & 14 & 14 & 14 & 14 \\
\hline \multirow{14}{*}{2} & $2-1$ & 186 & 287 & $\mathrm{~F}$ & 508 & 661 & 1.2 & 1.3 & 0.9 & 1 & 1 & 6 & 4 & 4 \\
\hline & $2-2$ & 53 & 55 & $\mathrm{~F}$ & 451 & 509 & 1.2 & 1.3 & 0.4 & 3 & 5 & 5 & 5 & 11 \\
\hline & $2-3$ & 30 & 3 & $\mathrm{~F}$ & 475 & 659 & 1.3 & 1.4 & 1.2 & 2 & 2 & 3 & 1 & 2 \\
\hline & $2-4$ & 30 & 3 & $\mathrm{M}$ & 204 & 245 & 0.9 & 1.0 & 0.7 & 14 & 14 & 14 & 13 & 10 \\
\hline & $2-5$ & 9 & 4 & $\mathrm{M}$ & 319 & 287 & 1.0 & 0.9 & -0.4 & 10 & 13 & 10 & 14 & 14 \\
\hline & $2-6$ & 4 & 0 & M & 336 & 435 & 1.0 & 1.1 & 0.9 & 9 & 7 & 9 & 9 & 5 \\
\hline & $2-7$ & 3 & 8 & M & 374 & 512 & 1.0 & 1.1 & 1.1 & 8 & 4 & 11 & 6 & 3 \\
\hline & $2-8$ & 1 & 14 & $\mathrm{~F}$ & 394 & 502 & 1.3 & 1.4 & 0.9 & 6 & 6 & 1 & 2 & 6 \\
\hline & $2-9$ & 1 & 1 & $\mathrm{~F}$ & 386 & 366 & 1.2 & 1.0 & -0.2 & 7 & 10 & 4 & 10 & 12 \\
\hline & $2-10$ & 0 & 1 & M & 225 & 345 & 0.9 & 1.1 & 1.5 & 13 & 11 & 13 & 7 & 1 \\
\hline & $2-11$ & 0 & 1 & M & 294 & 370 & 1.1 & 1.1 & 0.8 & 11 & 8 & 8 & 8 & 7 \\
\hline & $2-12$ & 0 & 0 & $\mathrm{~F}$ & 248 & 304 & 0.9 & 1.0 & 0.7 & 12 & 12 & 12 & 11 & 8 \\
\hline & $2-13$ & 0 & 0 & $\mathrm{~F}$ & 425 & 520 & 1.3 & 1.3 & 0.7 & 4 & 3 & 2 & 3 & 9 \\
\hline & $2-14$ & 0 & 4 & M & 403 & 369 & 1.1 & 1.0 & -0.3 & 5 & 9 & 7 & 12 & 13 \\
\hline \multirow{14}{*}{3} & $3-1$ & 400 & 203 & $\mathrm{M}$ & 313 & 354 & 1.2 & 1.1 & 0.4 & 12 & 10 & 5 & 7 & 11 \\
\hline & $3-2$ & 78 & 213 & $\mathrm{M}$ & 385 & 477 & 1.1 & 1.1 & 0.8 & 5 & 4 & 6 & 9 & 6 \\
\hline & $3-3$ & 58 & 31 & $\mathrm{~F}$ & 360 & 470 & 1.1 & 1.2 & 1.0 & 7 & 5 & 10 & 4 & 2 \\
\hline & $3-4$ & 9 & 83 & $\mathrm{M}$ & 495 & 616 & 1.2 & 1.3 & 0.8 & 2 & 1 & 2 & 2 & 5 \\
\hline & $3-5$ & 7 & 8 & $\mathrm{~F}$ & 335 & 402 & 1.0 & 1.0 & 0.7 & 8 & 9 & 14 & 13 & 7 \\
\hline & $3-6$ & 6 & 2 & M & 474 & 615 & 1.2 & 1.4 & 0.9 & 3 & 2 & 1 & 1 & 3 \\
\hline & $3-7$ & 3 & 12 & M & 362 & 463 & 1.1 & 1.2 & 0.9 & 6 & 7 & 7 & 6 & 4 \\
\hline & $3-8$ & 3 & 2 & M & 511 & 603 & 1.2 & 1.2 & 0.6 & 1 & 3 & 3 & 5 & 9 \\
\hline & $3-9$ & 2 & 0 & $\mathrm{M}$ & 324 & 319 & 1.0 & 0.9 & -0.1 & 10 & 13 & 13 & 14 & 14 \\
\hline & $3-10$ & 1 & 1 & $\mathrm{~F}$ & 327 & 438 & 1.2 & 1.2 & 1.0 & 9 & 8 & 4 & 3 & 1 \\
\hline & $3-11$ & 1 & 1 & M & 289 & 317 & 1.1 & 1.1 & 0.3 & 13 & 14 & 11 & 12 & 13 \\
\hline & $3-12$ & 0 & 4 & $\mathrm{~F}$ & 392 & 464 & 1.1 & 1.1 & 0.6 & 4 & 6 & 8 & 8 & 8 \\
\hline & $3-13$ & 0 & 1 & M & 285 & 327 & 1.1 & 1.1 & 0.5 & 14 & 12 & 9 & 10 & 10 \\
\hline & 3-14 & 0 & 0 & M & 318 & 352 & 1.0 & 1.1 & 0.4 & 11 & 11 & 12 & 11 & 12 \\
\hline \multirow{14}{*}{4} & $4-1$ & 334 & 334 & $\mathrm{~F}$ & 435 & 571 & 1.1 & 1.2 & 1.0 & 2 & 1 & 9 & 2 & 1 \\
\hline & $4-2$ & 50 & 81 & $\mathrm{~F}$ & 415 & 514 & 1.0 & 1.0 & 0.8 & 5 & 3 & 12 & 9 & 5 \\
\hline & $4-3$ & 3 & 17 & M & 391 & 381 & 1.1 & 1.0 & -0.1 & 8 & 11 & 4 & 12 & 11 \\
\hline & 4-4 & 2 & 0 & M & 339 & 403 & 1.1 & 1.1 & 0.6 & 12 & 9 & 10 & 7 & 7 \\
\hline & $4-5$ & 1 & 3 & $\mathrm{~F}$ & 314 & 369 & 1.0 & 0.9 & 0.6 & 14 & 12 & 14 & 13 & 8 \\
\hline & 4-6 & 1 & 1 & M & 479 & 513 & 1.2 & 1.1 & 0.2 & 1 & 4 & 1 & 5 & 9 \\
\hline & $4-7$ & 1 & 0 & $\mathrm{~F}$ & 416 & 399 & 1.2 & 1.0 & -0.1 & 4 & 10 & 2 & 8 & 12 \\
\hline & $4-8$ & 0 & 1 & M & 425 & 543 & 1.2 & 1.2 & 0.9 & 3 & 2 & 3 & 1 & 2 \\
\hline & $4-9$ & 0 & 2 & $\mathrm{~F}$ & 360 & 451 & 1.1 & 1.1 & 0.8 & 11 & 7 & 6 & 3 & 3 \\
\hline & $4-10$ & 0 & 0 & $\mathrm{M}$ & 399 & 497 & 1.1 & 1.1 & 0.78 & 7 & 5 & 8 & 6 & 4 \\
\hline & $4-11$ & 0 & 0 & M & 368 & 453 & 1.1 & 1.1 & 0.7 & 10 & 6 & 7 & 4 & 6 \\
\hline & $4-12$ & 0 & 1 & $\mathrm{~F}$ & 410 & 429 & 1.0 & 1.0 & 0.2 & 6 & 8 & 13 & 10 & 10 \\
\hline & $4-13$ & 0 & 0 & M & 330 & 315 & 1.1 & 1.0 & -0.2 & 13 & 14 & 5 & 11 & 13 \\
\hline & 4-14 & 0 & 1 & $\mathrm{~F}$ & 391 & 354 & 1.0 & 0.9 & -0.4 & 9 & 13 & 11 & 14 & 14 \\
\hline
\end{tabular}


started with the triggering strings being carefully placed into the tanks and fish had continuous access to two self-feeders filled with food during the first 14 days of the experiment, hereafter called Period 1 (28 April 2009 to 12 May 2009). On day 15 of the experiment the feeder in each tank that had received the highest number of trigger actuations during Period 1 was emptied. This feeder is hereafter called initially preferred feeder (IPF). The other feeder was kept filled and is called kept filled feeder (KFF). Thus, for 14 days, from day 15 to day 28 (Period 2, 12-25 May 2009) trigger actuations on IPF were never rewarded while actuations on KFF were always rewarded.

\subsection{Data analysis}

All videos were analysed in order to identify the individuals performing trigger actuations and fish swimming behaviour during actuations. Trigger actuations were recorded continuously throughout the experimental period and the identity of the triggering fish was determined in approximately $90 \%$ of the cases (the remaining $10 \%$ without fish ID was not included in the analyses). The number of trigger actuations per individual was used to calculate the proportional contribution of an individual fish to the total number of trigger actuations within its group over the entire experimental period and to assign the individual to one of the categories: high-triggering $(<25 \%$ actuations, HTF), low-triggering ( $>25 \%$, LTF) and zero-triggering (0\%, ZTF) fish (Coves et al. 2006; Millot et al. 2008; Millot and Bégout 2009).

In order to study whether cod learnt to associate the triggering behaviour of other individuals with food and respond to the behaviour per se by swimming toward the feeding area regardless of food delivery, we analyzed group behaviour on the first 10 actuations of the IPF during Period 2, i.e. with unrewarded actuations. The number of individuals in the feeding area (downstream of the self-feeder device in the image) was recorded $2 \mathrm{~s}$ before and $4 \mathrm{~s}$ after actuation.

At the end of the experiment all individuals were killed with a lethal dose of methomidate, measured for length and total weight, and their sex determined. Finally, individual body condition factor $(K)$ and specific growth rate $(S G R, \%$ body weight per day) were calculated using the following formulas:

$$
K=100 W L^{-3}
$$

where $W$ is the wet body weight ( $\mathrm{g}$ ) and $L$ the total body length (cm);

$$
S G R=100\left(\operatorname{Ln} W_{f}-\operatorname{Ln} W_{i}\right) t^{-1}
$$

where $W_{f}$ and $W_{i}$ are the final and the initial body weight (g) respectively, and $t$ is the total number of days between the two measuring days. All mean values are expressed with the standard error $( \pm \mathrm{SE})$.

\subsection{Statistics}

Data were checked for normality with a Shapiro-Wilk test and for homogeneity of variances with Bartlett's test. A nonparametric statistical test (Kruskal-Wallis, KW) was used to compare the number of fish (group composition) among the three triggering categories in each tank (HTF, LTF, ZTF) and to know if there was the same number of HTF, LTF and ZTF in each tank. All other data sets analyzed fulfilled the assumptions required for parametric tests to be used. For the number of daily trigger actuations by each group, a repeated-measures ANOVA was used to compare the differences between feeders (fixed factor, $N=2$ ), periods (fixed factor, $N=2$ ) and random effect of tanks (feeder nested within tanks, $N=4$ ). For the number of daily trigger actuations performed by each HTF in each tank, a repeated-measures ANOVA was used to compare the differences between feeders (fixed factor, $N=$ 2) and periods (fixed factor, $N=2$ ). Homogeneous groups were determined with a posteriori Newman and Keuls test (Dagnélie 1975). A paired $t$-test was used to test if the number of fish in the feeding area changed after unrewarded actuations. Spearman-ranks correlations were calculated for each experimental period, between the following variables: number of trigger actuations per individual and values and ranks of initial and final body weight, initial and final $K$, and $S G R$.

For all tests, significance threshold was $p<0.05$, and analyses were performed using the Statistica 7 software (Statsoft, USA).

\section{Results}

\subsection{Categories of triggering activity}

The first actuation occurred during the first minutes after the experiment started, for all fish groups. For both periods each group of $14 \mathrm{cod}$ was composed of 1 to $2 \mathrm{HTF}, 10$ to $11 \mathrm{LTF}$ and 1 to $3 \mathrm{ZTF}$, and no tank effects were found $(K W=1.17 ; p=0.76, d f=3, N=56)$.

\subsection{Daily feed demands for group and HTF fish in each tank}

The preference for one or the other feeder appeared after one to six days (Fig. 1). During Period 1 the preference for the Initially Preferred Feeder (IPF; $24 \pm 2$ actuations day ${ }^{-1}$ ) over the Kept Filled Feeder (KFF; $7 \pm 1$ actuations day $^{-1}$ ) was significant for all groups. During Period 2, when actuations on IPF were never rewarded, the preference of the fish shifted to KFF. The shift (when more than $50 \%$ of the trigger actuations per day are performed in the KFF) occurred one to eight days after IPF had been emptied (Fig. 1; black lines). Thus, during Period 2, KFF was utilised significantly more $(21 \pm 2$ actuations day $\left.{ }^{-1}\right)$ than IPF $\left(14 \pm 2\right.$ actuations day ${ }^{-1} ; F_{2.219}=23.4$, $p<0.01$ ).

In tank 1, the only HTF (Fish 1-1; Fig. 2) performed $87 \%$ of the total group trigger actuations. During Period 1, 62\% of its trigger actuations were on IPF. Two days after IPF was emptied the HTF presented a significantly lower utilisation of this feeder with only $24 \%$ of the actuations during Period $2(12 \%$ after the shift; $\left.F_{1.52}=10.9, p<0.01\right)$.

In tank 2, the only HTF (Fish 2-1; Fig. 2) performed $68 \%$ of the total group trigger actuations. Fish 2-1 performed $68 \%$ of its actuations on IPF during Period 1. One day after IPF was 


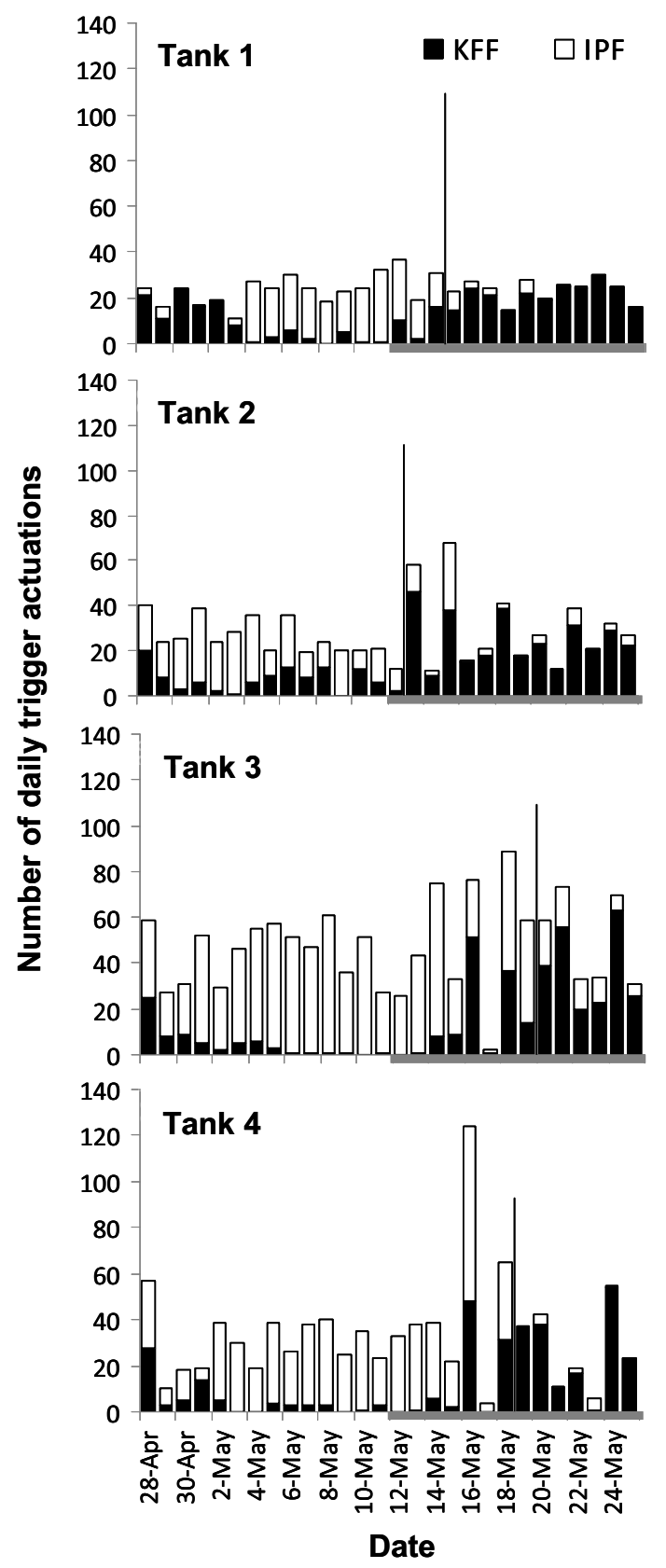

Fig. 1. Number of daily trigger actuations (per feeder) for each group. The grey bars on the $X$ axis represent the period when the initially preferred feeder (IPF) was empty (Period 2). The black lines represent the point in time when the preference shifted (always more than 50\% of the actuations per day) from the IPF to the kept filled feeder (KFF).

emptied, Fish 2-1 presented a significantly lower utilisation of this feeder and during Period 2 only $9 \%$ ( $6 \%$ after the shift) of its actuations were on $\operatorname{IPF}\left(F_{1.52}=33.5, p<0.001\right)$.

In tank 3 , there were 2 HTFs. Fish 3-1 performed 53\%, and Fish 3-2 26\% of the total group trigger actuations (Fig. 2). During Period 1, Fish 3-1 and Fish 3-2 performed 98\% and $72 \%$ of their actuations on IPF respectively. During the first days of Period 2, the triggering activity of Fish 3-1 was significantly reduced and its shift in feeder utilisation appeared
8 days after the beginning of Period 2. During this period Fish 3-1 still mostly used the IPF (66\%), but this was mainly due to two days with high activity on this feeder (Fig. 2). After the shift in feeder utilisation, the Fish 3-1 performed only $30 \%$ of its actuations on IPF $\left(F_{1.52}=4.2, p<0.05\right)$. Fish 3-2 presented a feeder shift utilisation 4 days after the beginning of Period 2, with $27 \%$ of its actuations on IPF during Period 2 and $15 \%$ after the shift $\left(F_{1.52}=13.5, p<0.001\right)$.

In tank 4 , the only HTF Fish $4-1$ performed $80 \%$ of the total group trigger actuations (Fig. 2). Fish 4-1 performed $84 \%$ of its actuations on IPF during Period 1. This fish presented a shift in feeder utilisation 6 days after the beginning of Period 2, and continued to actuate the IPF at $35 \%$. However, after the feeder shift, the utilisation of the IPF decreased significantly and represented only $3 \%$ of its actuations $\left(F_{1.52}=13.5, p<\right.$ $0.001)$.

\subsection{Response to triggering behaviour by other individuals}

During actuations of the unrewarded IPF in Period 2 other individuals often still approached the feeding area as if expecting food to fall. On the first 10 actuations after this feeder had been emptied, the number of fish in the feeding area was significantly higher after actuations than before actuation in all groups (tank 1: $t=-9.73, p<0.0001$; tank 2: $t=-3.07$, $p<0.05$; tank 3: $t=-2.58, p<0.05$; tank 4: $t=-4.83$, $p<0.001$, Fig. 3). Similar behaviour was also observed when triggering attempts failed to activate the feeder, but this was not quantified.

\subsection{Correlations between fish feeding behaviour and individual phenotypic characteristics}

In tanks 1, 2 and 4, all HTFs were females, and the highesttriggering individual in each of these tanks was ranked highest or second highest for initial weight in its group, and highest for final weight (Table 1). This pattern was not found in tank 3 , where the two HTFs were males with lower ranks for initial and final weight (Table 1). During Period 1, the number of trigger actuations by one individual was correlated with the final body weight and $K, S G R$ and with the individual's rank of initial and final body weight and SGR (Table 2). During Period 2, the number of trigger actuations by one individual was correlated with initial and final body weight, final $K$ and $S G R$. During the same period, the number of trigger actuations by one individual was correlated to the rank of these same variables excepted for the final $K$ (Table 2 ).

\section{Discussion}

The present study demonstrates that the individuals in a group of Atlantic cod actuate the self-feeder at very different rates, with a few high triggering individuals (HTF) performing the majority of actuations. This observation is in accordance with what has been found for other species such as sea bass (Millot and Bégout 2009), rainbow trout (Brännäs and Alanärä 1994; Alanärä and Brännäs 1996, 1997) and Arctic 
a.

Tank 1

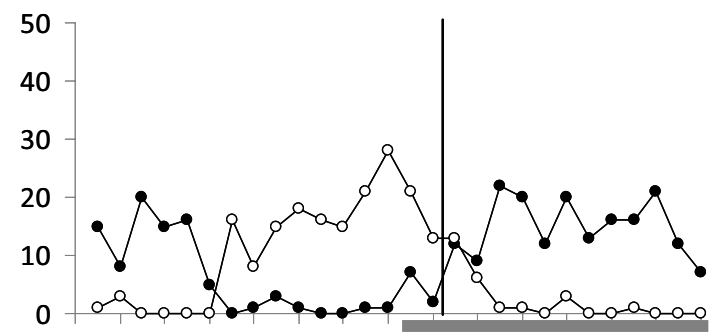

Tank 2

- Fish 2-1 KFF $\quad-0$-Fish 2-1 IPF

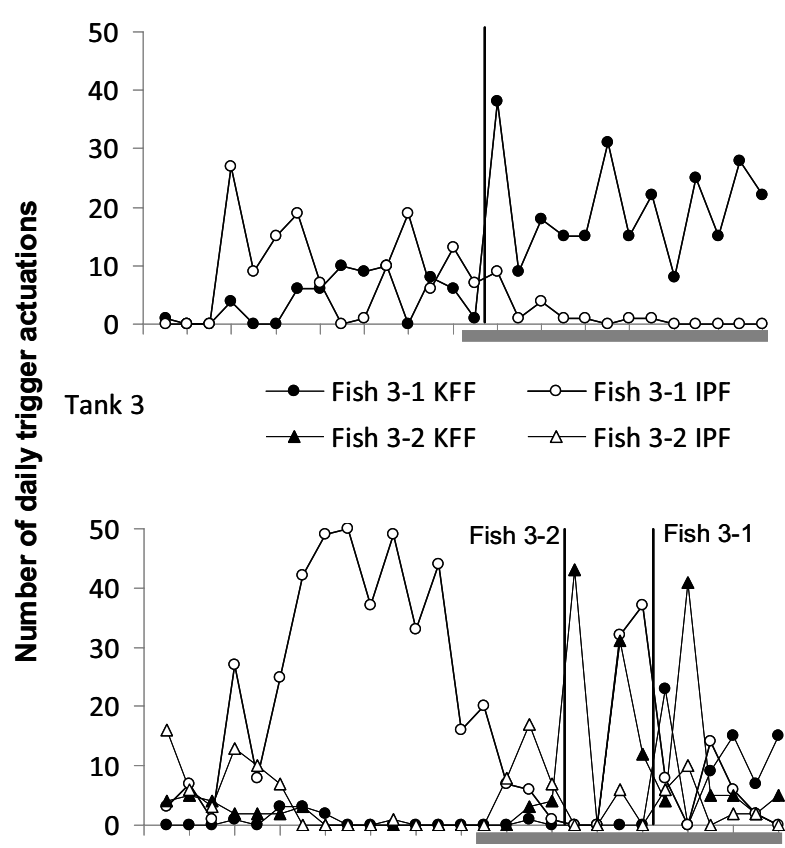

Tank $4 \quad-$ Fish 4-1 KFF $\quad$ - F Fish 4-1 IPF

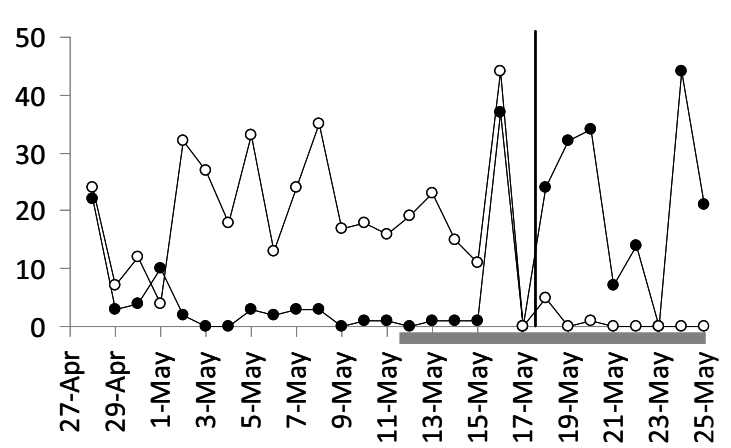

b.

\section{Sum of Low Triggering Fish}
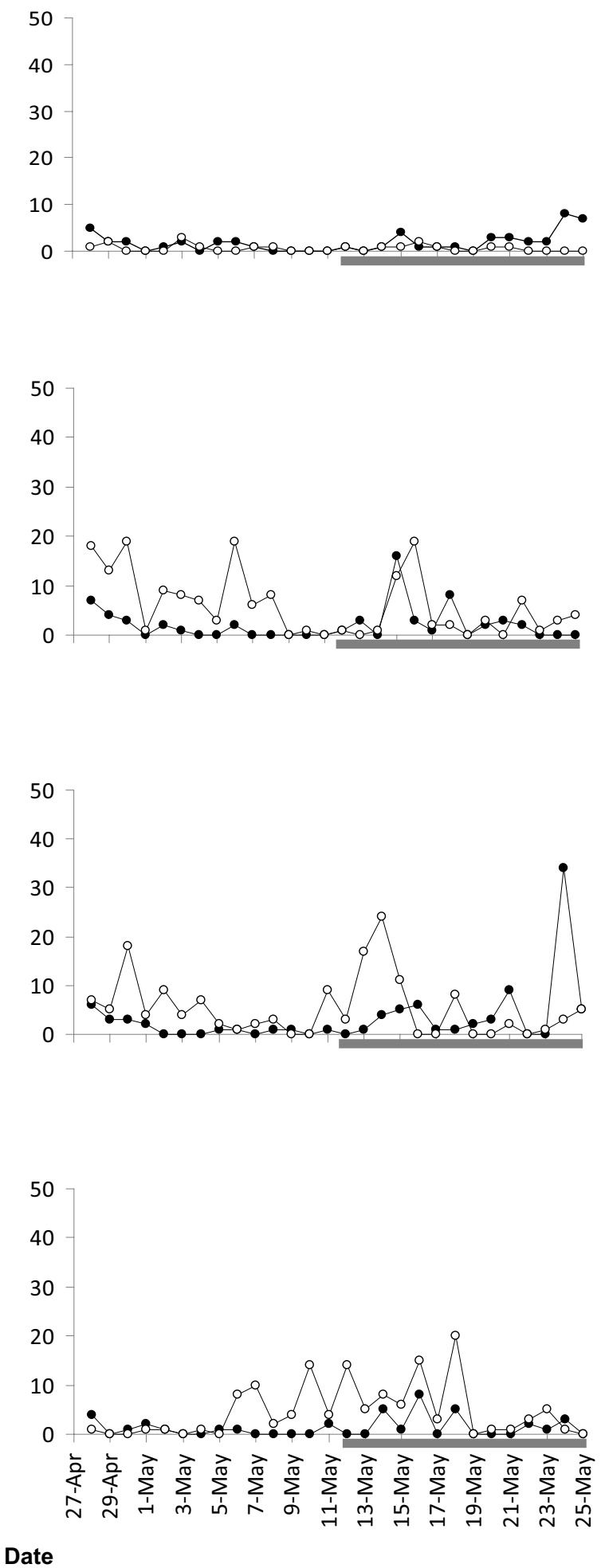

Fig. 2. Number of daily trigger actuations (per feeder) for high triggering fish (HTF, a) and remaining individuals (sum of low triggering fish, sum LTF, b) for tank 1, 2, 3 and 4 . The grey bars on the $X$ axis represent the period when the initially preferred feeder (IPF) was empty (Period 2). The black lines represent the point in time when the preference of each HTF shifted (always more than 50\% of the actuations per day) from IPF to KFF. 
Table 2. A Spearman correlation $(r)$ matrix values between the number of trigger actuations per individual for each experimental period (Period 1: P1; Period 2: P2) and the values and individual rank of each measured fish phenotypic characteristics (initial and final body weight, body condition factor $(K), S G R)$. Negative correlations between trigger actuations number and rank are due to the highest ranked individual being represented by the lowest number, i.e. the fish with the highest initial weight is ranked $1, N=56$, the significant correlations are in bold $(p<0.05)$.

\begin{tabular}{lllllllllll}
\hline & \multicolumn{3}{c}{ Variables } & \multicolumn{4}{c}{ Ranks of variables } \\
\hline Trigger actuations & \multicolumn{2}{c}{ Body weight } & \multicolumn{2}{c}{$K$} & & $S G R$ & \multicolumn{2}{c}{ Body weight } & & $K$ \\
\hline & Initial & Final & Initial & Final & & Initial & Final & Initial & Final \\
\hline$P 1$ & 0.24 & $\mathbf{0 . 3 7}$ & 0.13 & $\mathbf{0 . 2 9}$ & $\mathbf{0 . 3 0}$ & $\mathbf{- 0 . 3 3}$ & $-\mathbf{0 . 4 0}$ & -0.08 & -0.22 & $-\mathbf{0 . 2 6}$ \\
$P 2$ & $\mathbf{0 . 3 0}$ & $\mathbf{0 . 4 1}$ & 0.09 & $\mathbf{0 . 2 7}$ & $\mathbf{0 . 2 9}$ & $-\mathbf{0 . 3 8}$ & $-\mathbf{0 . 4 0}$ & -0.02 & -0.17 & $-\mathbf{0 . 2 8}$ \\
\hline
\end{tabular}

charr (Brännäs and Alanärä 1993; Alanärä and Brännäs 1996, 1997). Even if no agonistic interaction between fish was observed during triggering actuation and food delivery, it is probable that the status of HTF in the group was due to large body size and high social status. In particular, in social hierarchies the dominant fish generally gain a higher share of the available amount of food than the non-dominants and are characterised by a better growth rate (Metcalfe et al. 1989; Brännäs and Alanärä 1994; Alanärä and Brännäs 1996). In the present study, this seemed to be the case for all HTF females.

In one tank out of four ( $\operatorname{tank} 3$ ), the relationship between triggering activity and rank of size and growth rate was not clear, suggesting that there may be factors other than social status that explain the triggering activity of an individual. As showed by Anthouard et al. (1986) the difference in behaviour toward the trigger could be explained by the efficiency with which fish used the trigger and which could depend on the particular ability of each individual to learn about its own behaviour. Instrumental learning is to some degree dependent on procedural learning, i.e. to develop the skill to perform the rewarded behaviour. Behavioural actions towards the feeder that are not performed correctly, such as "nosing" on the trigger instead of pulling it, are not rewarded (Fernö et al. 2011). Individual differences, in the ability of fish to learn to operate the feeder correctly may be an explanation as to why some individuals actuate the trigger more than others. However, the relatively low number of successful actuations by the LTF can also give them fewer learning opportunities to acquire these skills, and as curiosity for unrewarded feeder devices can drop within a few hours (Nilsson and Torgersen 2010), the LTF may experience fewer trials. The frequency at which LTFs and ZTFs tried but failed to activate the trigger is not known, as these attempts were not recorded. When instrumental learning occurs in a group, the behaviour-reward relationship is not straightforward (Fernö et al. 2011). Moreover, other types of learning such as Pavlovian and social learning may occur simultaneously, making the learning situation complex. In this study, the observation of other individuals approaching the feeding area during unrewarded trigger actuations of the empty feeder during Period 2, and also after failed actuation attempts, clearly showed their ability to associate the HTF behaviour with food.

The relatively high and stable number of daily actuations and the switch in feeder preference when the IPF was empty strongly indicate that actuations were mainly motivated by appetite. The HTF learnt to associate their behaviour (trigger actuation) with its consequence (food delivery), and when this relationship was no longer valid for the empty IPF, i.e.

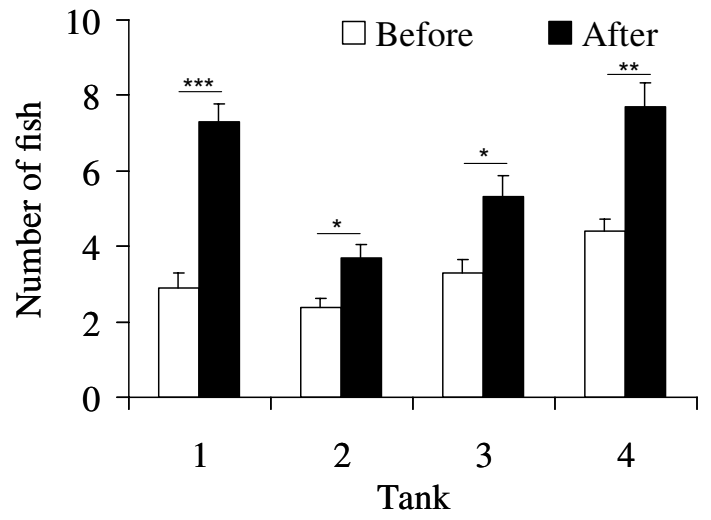

Fig. 3. Mean $( \pm \mathrm{SE})$ number of fish in the feeding area $2 \mathrm{~s}$ before and $4 \mathrm{~s}$ after the first 10 unrewarded actuations of the IPF during Period 2. Significant differences: $*<0.05 ; * *<0.001 ; * * *<0.0001$.

during Period 2, they behaved accordingly with a decreasing frequency of actuations on this feeder and an increasing frequency on the KFF. The switch in preference after the change in content of the IPF demonstrates that cod can update information and learn which feeders offer a reward, and thus may discriminate between feeders on the basis of their content. However, even with an extreme change (food to no food) it took up to eight days before the preference switched over to the filled feeder. This time is similar to that found in other species given the choice of two or more different food types (Sánchez-Vázquez et al. 1998; Guerden et al. 2005; Montoya et al. 2011). Even after the switch in feeder preference cod continued to actuate the empty feeder, although at a lower frequency. In experiments where fish can chose between two or more self-feeders containing food with different nutritional composition (e.g. Sánchez-Vázquez et al. 1998; Aranda et al. 2000), interpreting the proportion of actuations on each feeder as reflecting the fish's "choice" or need for this nutrient may thus lead to wrong conclusions as at least for cod all actuations do not reflect a nutritional need, e.g. actuations on empty feeders.

In conclusion, the present study clearly demonstrates that self-feeding as a method to study food preferences in groups of fish has several limitations that need to be taken into account when designing experiments and during interpretation of data. First, a strong preference for the filled over the empty feeder during Period 2 suggests that triggering activity is mainly motivated by appetite after the initial period (before learning) where curiosity is the main driver 
(Nilsson and Torgersen 2010). However, all HTF occasionally triggered the empty feeder during Period 2 which may be due to fish testing if this feeder delivers food again. Occasional actuations on a non-preferred feeder may be sampling for information of environmental change rather than a desire for the feeder content. Secondly, all groups showed a preference for one feeder over the other when the two feeders had exactly the same content during Period 1, meaning that feeder preference is not solely reflecting food preference. Controlling for this, for instance by switching food type between feeders, is therefore crucial. The time for cod to switch feeder preference when the preferred feeder was emptied was one to eight days, and actuations of the empty feeder occurred throughout the experiment. The long learning period after switching the content between feeders, where the food choice is not indicating the preference of the fish, will lead to a high degree of uncertainty of preference and will necessitate long duration experiments. Thirdly, only one or two individuals, in most cases the largest female, are responsible for triggering self-feeders in most tanks, thus, preferences may not be representative for an average member of the group. If the aim is to determine the preference for the average cod multiple representative fish should to be kept isolated in separate tanks, with self-feeders containing each food option, on each tank.

Acknowledgements. We wish to thank M. de Vareilles for editing the English of this manuscript. This study has been carried out with financial support from Institute of Marine Research, Norway, Research Council of Norway, and the Commission of the European Communities, through Cost Action 867, Short Term Scientific Mission allocated to S.M. It does not necessarily reflect the Commission of the European Communities views and in no way anticipates the Commission's future policy in this area.

\section{References}

Alanärä A., 1996, The use of self feeders in rainbow trout (Oncorhynchus mykiss) production. Aquaculture 145, 1-20.

Alanärä A., Brännäs E., 1993, A test of the individual feeding activity and food size preference in rainbow trout. Aquac. Internat. 1, $47-54$.

Alanärä A., Brännäs E., 1996, Dominance in demand-feeding behaviour in Arctic charr and rainbow trout: the effect of stocking density. J. Fish Biol. 48, 242-254.

Alanärä A., Brännäs E., 1997, Diurnal and nocturnal feeding activity in Arctic char (Salvelinus alpinus) and rainbow trout (Oncorhynchus mykiss). Can. J. Fish. Aquat. Sci. 54, 2894-2900.

Alanärä A., Winberg S., Brännäs E., Kiessling K., Höglund A., Elofsson U., 1998, Feeding behaviour, brain serotonergic activity and energy reserves of Arctic char (Salvelinus alpinus) within a dominance hierarchy. Can. J. Fish. Aquat. Sci. 76, 212-220.

Anthouard M., Desportes C., Kentouri M., Divanach P., Paris J., 1986, Étude des modèles comportementaux manifestés au levier par Dicentrarchus labrax, Diplodus sargus, Puntazzo puntazzo, Sparus aurata, et Lithognatus mormyrus (Poissons téléostéens), placés dans une situation de nourrissage auto-contrôlé. Biol. Behav. 11, 97-110.

Aranda A., Sanchez-Vazquez F.J., Zamora S., Madrid J.A., 2000, Self-design of fish diets by means of self-feeders: validation of procedures. J. Physiol. Biochem. 56, 155-166.
Aranda A., Sanchez-Vazquez F.J., Madrid J.A., 2001, Effect of shortterm fasting on macronutrient self-selection in sea bass. Physiol. Behav. 73, 105-109.

Attia J., Millot S., Di-Poï C., Bégout M.L., Noble C., SanchezVazquez F.J., Terova G., Saroglia M., Damsgard B., 2012, Demand feeding and welfare in farmed fish. Fish Physiol. Biochem. DOI: 10.1007/s10695-011-9538-4.

Azzaydi M., Madrid J.A., Zamora S., Sanchez-Vazquez F.J., Martinez F.J., 1998, Effect of three feeding strategies (automatic, ad libitum demand-feeding and time-restricted demand-feeding) on feeding rhythms and growth in European sea bass (Dicentrarchus labrax L.). Aquaculture 163, 285-296.

Brännäs E., Alanärä A., 1993, Monitoring the feeding activity of individual fish with a demand feeding system. J. Fish Biol. 42, 209215.

Brännäs E., Alanärä A., 1994, Effect of reward level on individual variability in demand feeding activity and growth rate in Arctic charr and rainbow trout. J. Fish Biol. 45, 423-434.

Covès D., Beauchaud M., Attia J., Dutto G., Bouchut C., Bégout Anras M.L., 2006, Long-term monitoring of individual fish triggering activity on a self-feeding system: An example using European sea bass (Dicentrarchus labrax). Aquaculture 253, 385-392.

Dagnélie P., 1975, Théorie et méthodes statistiques, Applications agronomiques, Vol. 2. Presses Agronomiques de Gembloux, Gembloux.

Davey G., 1989, Ecological learning theory. Routledge, London \& New York.

Di-Poï C., Attia J., Bouchut C., Dutto G., Covès D., Beauchaud M., 2007, Behavioural and neurophysiological responses of European sea bass groups reared under food constraint. Physiol. Behav. 90, $559-566$.

Fernö A., Huse G., Jakobsen P.J., Kristiansen T.S., Nilsson J., 2011, Fish behaviour, learning, Aquaculture and Fisheries. In: Brown C., Laland K., Krause J. (eds.), Fish cognition and behavior 2nd edn., Blackwell, Oxford, pp. 447-502.

Geurden I., Cuvier A., Gondouin E., Olsen R.E., Ruohonen K., Kaushik S., Boujard T., 2005, Rainbow trout can discriminate between feeds with different oil sources. Physiol. Behav. 85, 107114.

Metcalfe N.B., Huntingford F.A., Graham W.D., Thorpe J.E., 1989, Early social status and the development of life-history strategies in Atlantic salmon. Proc. R. Soc. Lond. B Biol 236, 7-19.

Millot S., Bégout M.L., 2009, Individual fish rhythm directs group feeding: a case study with sea bass juveniles (Dicentrarchus labrax) under self-demand feeding conditions. Aquat. Living Resour. 22, 363-370.

Millot S., Bégout M.L., Person-Le Ruyet J., Breuil G., Di-Poï C., Fievet J., Pineau P., Roué M., Sévère A., 2008, Feed demand behavior in sea bass juveniles: effects on individual specific growth rate variation and health (inter-individual and inter-group variation). Aquaculture 274, 87-95.

Montoya A., Alves Martins D., Yufera M., Sánchez-Vázquez F.J., 2011, Self-selection of diets with different oil oxidation levels in gilthead seabream (Sparus aurata). Aquaculture 314, 282-284.

Nilsson J., Torgersen T., 2010, Exploration and learning of demandfeeding in Atlantic cod (Gadus morhua). Aquaculture 306, 384 387.

Sánchez-Vázquez F.J., Yamamoto T., Akiyama T., Madrid J.A., Tabata M., 1998, Macronutrient self-selection through demand feeders in rainbow trout. Physiol. Behav. 66, 45-51.

Skinner B.F., 1938, The behavior of organisms. Appleton-CenturyCrofts, NY. 